\title{
Engagement en el trabajo
}

\section{Paulo Cesar Porto-Martins*}

Doutorando na Universidad Autónoma de Madrid, Madri, Espanha

\section{Pedro Guilherme Basso-Machado**}

Doutorando na Universidad Autónoma de Madrid, Madri, Espanha

SORIA, Maria Salanova; SCHAUFELI, Wilmar. EI Engagement en el trabajo: cuando el trabajo se convierte en pasión. Madrid: Alianza Editorial, 2009. 320 páginas

O livro "Engagement en el Trabajo", escrito pelos professores Marisa Salanova Soria e Wilmar Schaufeli, apresenta conteúdos essenciais para diversas áreas da psicologia como, por exemplo, a Psicologia Organizacional e do Trabalho (POT), a Psicologia Clínica e para Psicologia Positiva. A publicação desta obra foi realizada pela editora Alianza Editorial localizada em Madri, no ano de 2009, e conta com um total de 320 páginas dividas em: prólogo, introdução e sete capítulos. Marisa Salanova Soria é catedrática em Psicologia Social, com "Master" e Doutorado em Psicologia Organizacional e do Trabalho. Salanova coordena uma equipe de Work Organization Network e possui mais de 200 publicações nacionais e internacionais.

Wilmar B. Schaufeli é Professor de Psicologia Organizacional e do Trabalho na Universidade de Utrecht na Holanda e atua como consultor Sênior no "Centro para Comportamento Organizacional" neste mesmo país. Schaufeli possui doutorado em Psicologia da Saúde e é licenciado em Psicologia da Saúde Ocupacional. Nas últimas duas décadas, publicou mais de 300 artigos científicos, capítulo e livros sendo que muitos deles sobre engagement no trabalho, tornando-o atualmente uma referencia mundial sobre o tema.

Schaufeli é um dos autores mais citados em artigos científicos referentes a síndrome de burnout (e outros acometimentos ligados ao mundo laboral como por exemplo workaholice flow) e precursor do constructo engagement no trabalho, além de ser autor do UWES (Utrecht Work Engagement Scale) instrumento mundialmente utilizado para a avaliação de engagement no trabalho, que já foi traduzido para 19 
idiomas (inclusive português do Brasil) e conta com uma base de dados internacional de aproximadamente 30.000 trabalhadores.

Em termos gerais, o livro discorre sobre engagement no trabalho, suas conceituações, histórico assim como contextualizações teóricas, empíricas e práticas. Pode-se compreender o termo basicamente como um estado psicológico positivo, relacionado com o trabalho, persistente no tempo, de natureza individual, social e organizacional. Este constructo é caracterizado por três dimensões: Vigor, Dedicação e Absorção. Vigor se caracteriza por altos níveis de energia, persistência, desejo de esforçar-se e resiliência mental em quanto se trabalha. Já a Dedicação remete ao sentimento de estar plenamente envolvido realizando o trabalho, inspiração, orgulho, desafio, objetivo, significado e entusiasmo. E por último, Absorção que é caracterizada por estar plenamente concentrado e feliz realizando o trabalho, sensação que o tempo "passa voando" e dificuldade de se "desligar" do trabalho.

O engagement no trabalho tem uma estreita relação com um fenômeno já estudado há mais de um quarto de século por diversos pesquisadores, a síndrome de burnout. Para se compreender melhor, o engagement no trabalho acarreta um processo de melhora da saúde laboral, o que seria o inverso da deterioração da saúde que é a causa da síndrome de burnout.

Este conceito vem de uma nova tendência da Psicologia moderna, a chamada "Psicologia Positiva", que busca identificar e desenvolver as fortalezas e o funcionamento ótimo do ser humano, mas ainda é pouco estudado, principalmente no Brasil. Esta corrente é uma resposta a uma tendência negativista dos estudos sobre os fenômenos psicológicos, uma vez que a grande maioria de trabalhos e estudos empíricos dão prioridade a aspectos negativos do ser humano em geral (modelo médico tradicional).

Uma das características marcantes do livro é o cuidado em introduzir claramente os temas abordados, pois sempre que possível os termo técnicos são definidos e contextualizados, o que possibilita ao leitor "leigo" compreender e acompanhar as ideias expostas. Além desta característica, nota-se vasta presença de fundamentação científica, o que proporciona ao leitor "avançado" aprofundar e atualizar seus conhecimentos de forma criteriosa e científica.

O prólogo, realizado pelo professor Eugenio Garrido da Universidade de Salamanca, aborda principalmente o conceito de autoeficácia, conceito este que será amplamente utilizado no decorrer do livro. Já na introdução é apresentado um breve resumo dos assuntos que serão abordados ao longo dos sete capítulos que compõem a obra. Ainda na parte introdutória é destacada a importância de manter o termo 
engagementno trabalho em seu original (inglês) e não realizar traduções para o mesmo.

No primeiro capítulo, intitulado "Mudanças e novas demandas no mundo do trabalho", são abordados vários aspectos do mundo laboral como a historia do trabalho, a relação desta com os indivíduos, a evolução dos contextos organizacionais, temas relacionados a acordos de trabalho, sofrimento laboral, aspectos positivos no trabalho (engagement), competências dos trabalhadores, "empowerment" e "empregabilidade".

De forma geral, este primeiro capítulo, faz uma revisão histórica do trabalho e sua relação com aspectos psicológicos do ser humano e vai até a visão mais atual, que é da saúde não mais como mera ausência de doenças dentro das organizações.

O seguinte capítulo "Psicologia positiva e ocupacional positiva: uma nova perspectiva" é o menor do livro, com apenas 20 laudas. Neste, é ressaltado que a psicologia da saúde tradicionalmente se concentra na falta de saúde (seguindo o modelo médico tradicional) e não a concepção mais moderna de saúde fornecida pela OMS que conceitua saúde como um estado de bem-estar total que inclui aspectos físicos, mentais e sociais, não apenas a mera ausência de doença ou transtornos.

Faz-se ainda uma introdução no conceito de Psicologia Positiva destacando a trajetória deste conceito até os dias atuais. Após abordarem a Psicologia Positiva, os autores destacam que a POP (Psicologia Ocupacional Positiva) deve ser o atual foco das organizações, ressaltando a importância do setor de $\mathrm{RH}$ para implementação deste novo paradigma.

No terceiro capítulo, intitulado "O que é engagement no trabalho? Conceito e Medida.", é exposta a origem do termo engagementno trabalho, tanto de acordo com conceitos de consultorias quanto definições acadêmicas, suas primeiras e atuais definições, diferentes instrumentos de avaliação, além de um panorama de publicações que envolvem o conceito. Outro aspecto relevante do capítulo é que se expõem conceitos associados com engagement no trabalho, dando uma relevância prática ao termo.

No quarto capítulo "Teorias psicossociais sobre o engagement" o conceito de engagement no trabalho é revelado desde um ponto de vista psicossocial, apresentando o modelo de Demandas e Recursos Laborais (DRL), que contempla aspectos positivos e negativos da atividade laboral. Ainda neste capítulo aparece a prática e útil ideia de "espiral de ganâncias", onde se explana as consequências de determinados comportamentos e atitudes em nível individual e organizacional. O capítulo todo apresenta, dentro do Modelo DRL, uma conexão dos 
conceitos apresentados e uma articulação destes entre si, denotando suas relações.

No capítulo seguinte "Intervenções individuais para incrementar o engagement", o mais extenso de todos, com 54 laudas, os autores indicam intervenções para o aumento dos níveis de engagement e outros estados psicológicos positivos (ex.: resiliência, auto eficácia, capital psicológico entre outros) em trabalhadores, tanto no que diz respeito a medidas preventivas (mais recomendáveis) quanto "curativas". As intervenções apontadas envolvem atividades comportamentais (tais como a atividade física, fortalecimento de redes sociais, autoconhecimento através da identificação e uso das fortalezas individuais, etc.), cognitivas (promoção de pensamentos positivos, estratégias de adaptação sociais, etc.) e volitivas (estabelecimento de metas pessoais, busca do sentimento de flow, etc.).

No sexto capítulo "Intervenções organizacionais para aumentar o engagement", seguindo uma linha lógica e indutiva, os autores abordam intervenções e estratégias, agora em nível organizacional, para a promoção do engagement no trabalho e outros estados psicológicos positivos. Apresentam-se conceitos de sinergias individuais, interpessoais e organizacionais. Explicam processos que envolvem a seleção, socialização e avaliação de pessoal (contrato psicológico, liderança transformacional, gestão de diversidade, relações interpessoais, desenvolvimento da Carrera profissional, auditorias, workshops, etc.) com objetivo de criar estas sinergias supracitadas. Tudo isto dentro do principio de que, criando engagement nos trabalhadores, criar-se-á um conjunto de sinergias e benefícios, consequências positivas em vários aspectos (produtividade, qualidade, etc.), para a própria organização.

O último capítulo "Um passo além: trabalhadores "engaged" e organizações saudáveis" aborda compreensões de uma organização considerada "saudável", explicando-se o que seria este tipo de organização, assim como trabalhadores que sejam engaged. Dentro desta perspectiva, utiliza todo o material lido anteriormente para integrar os conhecimentos até então observados pelo leitor, considerando o engagement no trabalho como um constructo individual e coletivo que deve proporcionar reflexões e direções para um modelo positivo de organização e empregado.

Resumindo-se, os autores apresentam uma contextualização do mundo laboral, seus aspectos, contextos e fatores psicológicos, para num outro momento introduzir as diversas concepções do termo engagement no trabalho. Após esta explanação dos autores frente aos leitores, são contempladas propostas práticas, de intervenções tanto a nível 
individual quanto organizacional, o que agrega um grande valor a obra tanto para gestores e profissionais de $\mathrm{RH}$ como para acadêmicos e pesquisadores em psicologia em termos gerais.

Esta obra propõe uma nova "visão" para os psicólogos que trabalham com o mundo organizacional, deixando de lado o modelo médico tradicional (tratar e evitar problemas, acometimentos e sofrimentos), mas potencializar aspectos positivos como vigor, dedicação e absorção, ou seja, engagement no trabalho. Isto tudo sempre buscando a promoção da saúde ocupacional que não deve se limitar ao modelo médico, mas sim considerar a promoção da saúde como um valor tanto crucial quanto estratégico (não como um gasto, mas como um investimento).

\section{Endereço para correspondência}

Paulo Cesar Porto-Martins

Brigadeiro A. Carlos Peralta, 959, Bairro Boa Vista, CEP 82560-030, Curitiba, PR, Brasil

Endereço eletrônico: paulocpmar@yahoo.com.br

Pedro Guilherme Basso Machado

Professor Raul Pinheiro Machado, 195, Bairro Bacacheri, CEP 82520-790, Curitiba, PR, Brasil

Endereço eletrônico: pgbmachado@yahoo.com.br

Recebido em: 13/08/2010

Aceito para publicação em: 15/08/2010

Acompanhamento do processo editorial: Ariane P. Ewald

\section{Notas}

*Psicólogo, Especialista em Didática do Ensino Superior - PUC-PR; Membro do GEPEB Grupo de Estudos e Pesquisas sobre Estresse e Burnout - CNPq; Docente da Faculdades Sant' Ana, Ponta Grossa, PR, Brasil;

**Psicólogo; Membro do GEPEB - Grupo de Estudos e Pesquisas sobre Estresse e Burnout. 